\title{
Rehabilitation of COVID 19 Patients, Bangladesh Perspective
}

\author{
MS RAHMAN
}

\begin{abstract}
:
The global outbreak of COVID 19 has created an unprecedented challenge to the society. America, Europe and India were catastrophic sufferers from this virus next to China. They had highest number of daily morbidity and mortality in the global context. Bangladesh is facing terrible experiences of dealing with this pandemic and making a tremendous turmoil in health and economic sector. Our healthcare system is overburdened with critically ill patients. Disability arising out of neurological, pulmonary, neuromuscular, and cognitive complications, need to be addressed by rehabilitation professionals. Many patients presenting with COVID-19 will have no specific airway clearance needs. There have been no reports of COVID-19 positive patients having high secretion loads that would require intensive chest physiotherapy or postural drainage. In Bangladesh in ICU settings physiatrist or physiotherapists are not directly involve in respiratory care management. In mild to moderate cases advice about a post-acute care
\end{abstract}

Introduction:

The panic of corona pandemic has shaken the world even the developed countries so strongly that health systems of most of the countries were not prepared to accommodate the needs. Bangladesh a low resource country in south Asia is facing acute shortage of supplies, hospital beds and ICU's.

COVID-19 (coronavirus disease 2019) is caused by SARS-CoV-2, a newly emergent coronavirus, which was first recognized in Wuhan, China, in December 2019. This is a betacoronavirus closely linked to the SARS virus founding on genetic sequencing. ${ }^{1}$ About $40 \%$ of patients developed mild symptoms, another $40 \%$ suffers moderately. $15 \%$ may need ICU or ventilation. Only have $5 \%$ have critical conditions with complications

Address of Correspondence: Professor Md. Shahidur Rahman, Professor of Physical Medicine and Rehabilitation, Bangabandhu Sheikh Mujib Medical University, Shahbag, Dhaka. Mobile: 01713030207,E-mail: shahidurpmrbd@gmail.com

Received: 22 August, 2020

Accepted: 29 August, 2021 breathing exercises, other musculoskeletal exercises, bed positioning and pressure sore care are helpful. In Bangladesh medical care facilities are not adequate in corona care hospitals especially in peripheral medical college or hospital. Many patients are dying of shortage in oxygen supplies and lack of availability of ICU. Post discharged plans of comprehensive rehabilitation are grossly neglected in discharged certificate. Our national guidelines on corona management do not have any instructions on rehabilitation management at any point. The objectives of this fast review article on corona pandemic are to highlight the global scenario and our limitations in the rehabilitation management of COVID 19 patients particularly post discharged patients and patients with long COVID complications.

Key words: COVID 19, Rehabilitation, Bangladesh perspective.

(J Bangladesh Coll Phys Surg 2022; 40: 52-56)

DOI: https://doi.org/10.3329/jbcps.v40i1.57059

likerespiratory failure, acute respiratory distress syndrome (ARDS), sepsis and septic shock, thromboembolism, and/or multi-organ failure, including acute kidney injury and cardiac injury ${ }^{2}$.

Over 200 countries in the world are facing this coronavirus pandemic crisis and created a panic as well as a unique challenge to the society. Global leaders realized with exigency the negligence in the health and health care delivery services in the past. Though China is the first affected country of this deadly virus has successfully controlled the transmission and death. Italy, UK, Spain and France were next sufferers with high death rate but effectively tamed the tenacious tenure. At present the United States, Brazil Mexico and India have highest positive case and deaths in the world. Conditions arising out of neurological, pulmonary, neuromuscular, and cognitive complications can be successfully approached by rehabilitation professionals and they can improve the quality of life of sufferers. Clinicians across the nation's rehabilitation system of 
developed countries have already begun working to initiate intensive care unit-based rehabilitation care and develop programs, settings, and specialized care to meet the short- and long-term needs of these individuals. ${ }^{3}$

\section{Rehabilitation concern of Europe}

Covid-19 has shown a bright light on the impressive work of National Health Services intensive care units (ICUs) around the UK. Now, as the first patients who have had the new virus and spent days ventilated in ICUs are discharged, the Chartered Society of Physiotherapy in UK predicts a "tsunami of rehabilitation needs." Already there are question marks about whether appropriate rehabilitation-physical, cognitive, and psychological could be made available for the huge numbers of patients who will need to deal with the enormous impact of a stay in critical care. ${ }^{4}$

\section{Highlighting rehabilitation needs}

National guidelines on clinical management of coronavirus Disease2021(COVID), published on $18^{\text {th }}$ May 2020 neither have any instructions on rehabilitation management of corona affected patients nor a 28 member list of contributors to prepare the guidelines include rehabilitation specialist. ${ }^{5}$ On the other hand World Health Organization on clinical management of COVID19 interim guidance $27^{\text {th }}$ May 2020 highlighted the importance of rehabilitation management. ${ }^{6}$ Caring for critically ill COVID 19 patients: quick guide for ICU care does not contain any discussion on rehabilitation need. We did not find any information or statistics on rehabilitation activities of COVID-19 patients from any corona dedicated hospitals during preparation of this manuscript. ${ }^{7}$

Identification of the presence of impairments related to physical function, respiratory function, cognition, nutrition, communication, swallow, activities of daily living and psychosocial needs (or any other impairment) is essential to formulate the rehabilitation plan.

Person's individual situation, including pre-admission status, social support, home environment and access to rehabilitation should be considered first. ${ }^{8}$ Emphasis should be given to older people, those with disability and those with comorbidities, who may have more complex requirements. Family members and caregivers should be involved in the assessment and decision-making regarding rehabilitation and discharge planning, ${ }^{9,10}$
Patients with severe COVID-19 require hospitalization and oxygen support. Those whose illness may be complicated by acute respiratory distress syndrome (ARDS), sepsis and septic shock, or multi-organ failure, including kidney, liver and cardiac injury will typically require invasive mechanical ventilation in the ICU. ${ }^{11}$, 12, 13, 14, 15 Mechanical ventilation, coupled with sedation and/or paralysis, as well as potentially prolonged bed rest and immobilization, can have many detrimental musculoskeletal effects including reduced muscle strength and physical function. ${ }^{16,17,18}$ Other effects may include impairments in respiratory function, cognitive status, swallow, and communication, as well as symptoms of delirium. In the long-term, the multifaceted aspects of post intensive care syndrome, which can persist for many months or years after discharge, may also manifest in reduced exercise capacity, impaired activities of daily living, and healthrelated quality of life. 19, 20,21, 22 Patients with severe COVID-19 who do not receive invasive mechanical ventilation, for non-availability of ICU or where illness severity does not warrant this, may also experience some degree of impaired physical and respiratory function, as well as psychosocial challenges, as a result of the illness and hospitalization. The rehabilitation needs associated with severe COVID-19 may be amplified by underlying morbidity and comorbidity. Pandemic-related prolonged containment measures can also exacerbate many of these problems for patients who are recovering from COVID-19 illness. The overall schedules of rehabilitation services are enormous in all stages of COVID 19 management. Rehabilitation must be recognized as an essential component of COVID-19 management which requires a planned accommodative working environment in the altered situation within the health care system. ${ }^{23}$,

\section{Interventions in severe cases}

When the patients with severe COVID-19 are receiving ventilator support, rehabilitation professionals can strongly support the acute respiratory care management ${ }^{24}$, and the maintenance and improvement of functioning to facilitate early recovery. Specialized rehabilitation professionals can provide interventions that assist in improving oxygenation, airway secretion clearance, and ventilation weaning, ${ }^{25}$. They can also play a role in promoting nutrition ${ }^{26}$ and prevention of aspiration pneumonia, especially post-intubation or in patients with 
a tracheostomy. ${ }^{27}$ When the patients have returned to a hospital ward or step-down facility or for patients where illness severity did not warrant admission to an intensive care unit, rehabilitation interventions may focus on addressing ongoing impairments in mobility, respiratory function, cognition, swallow and nutrition, and communication. ${ }^{28,29}$ Interventions during this period further promote independence with activities of daily living, and provide psychosocial support. Rehabilitation professionals also contribute significantly to discharge preparation and planning, which can be particularly complex for older patients and those with comorbidities. ${ }^{30}$ When discharged after prolonged hospital stay rehabilitation professionals can provide graded exercise, education on energy conservation, behavior modification, home modification. They can provide assistive products, as well as rehabilitation for any specific individual impairment. During the long-term recovery of severe COVID-19 illness, patients may benefit from pulmonary rehabilitative interventions, which target physical and respiratory impairments. These may include a combination of exercise, education, activity of daily living, and psychosocial support. ${ }^{31} \mathrm{In}$ the context of pandemic related constraints like physical distancing, limited human resources, limited public transport and infection risks tele-health is likely to be helpful following discharge. This could be extended to include remote exercise (e.g. "virtual group" education and exercise) and peer-to-peer support from COVID-19 patients who have received the appropriate training. Community based rehabilitations are often more practical to deliver longer-term care

Need of chest physiotherapy

Clinically moderate to severe cases of COVID 19 patients present with fever, dry cough and respiratory distress as preliminary symptoms. COVID 19 hospitalized patients are presenting with pneumonia features and bilateral patchy shadows or ground-glass opacity in the lungs found in HRCT. Though present with pneumonia features COVID-19 positive patients do not have high secretion loads that would require postural drainage. Some therapeutic interventions like postural drainage or pursed lip breathing during acute illness should be contraindicated. There may be patients with existing respiratory conditions who require personalized physiotherapy treatments which may include mechanical airway clearance. In this scenario, it is important that the risk and benefit of continuing with the regime are discussed with consultant respiratory clinicians/critical care consultants. ${ }^{32}$

Chest physiotherapy like postural drainage may be indicated if patients with COVID-19 present with airway secretions that they are unable to clear independently. Interventions should be based on clinical indicators, and may also be utilized in high risk individuals e.g. patients with existing comorbidities that may be associated with hyper secretion or ineffective cough. ${ }^{33}$ Physical interventions are unlikely to be beneficial in the acute stages. Physiotherapists will have a role in the rehabilitation of COVID-19 patients who have not returned to their functional baseline once they are no longer acutely unwell.

\section{When to start rehabilitation management}

Early mobilization with a focus on returning to functional activities reduces the length of hospital stay and minimizes functional decline. So early mobilization can help the patient to leave the ICU, and potentially have better long-term outcomes. This phase of management should incorporate a multi-disciplinary approach including measures to prevent avoidable physical and non-physical morbidity, support adequate nutrition and an individualized, structured rehabilitation program. During convalescence patients need passive, active assisted, active, or resisted joint range of motion exercises to maintain or improve joint integrity and range of motion and muscle strength; ${ }^{33}$ Physiotherapists can play a key role in the prevention of a range of complications including ventilator-associated pneumonias, secondary infections, contractures or pressure sores.Common modalities often used by respiratory physiotherapists may be contraindicated in the acute phase as they may further compromise the increased work of breathing.

\section{Positioning of the patient}

Mechanically ventilated COVID-19 patient need positioning as important procedure with regular turning to prevent atelectasis, optimize ventilation and prevent pressure sores. Positioning can include lateral (side lying) positioning but may also include prone positioning, which is well recognized to treat hypoxemic respiratory failure. Prone ventilation is ventilation that is delivered with the patient lying in the prone position is prone ventilation. This may improve gas exchanges, 
and improves oxygenation as well as outcome in the majority of patients with ARDS. Hypoxia associated with COVID-19 is better improved with prone ventilation ${ }^{34}$

Physical and rehabilitation medicine (PRM) have important role in rehabilitation of patients in the immediate post-acute phase ofCOVID-19. Following the acute phase of the pandemic there will be a surge in need for rehabilitation, including mobilization. The increased need for PRM efforts will last for months, if not years, including rehabilitation of secondary disorders, including post intensive care syndrome. ${ }^{35}$

Conclusion: Intervention of patients with COVID 19 disease should be very specific and individualized. Critical patients have coagulopathy, atelectasis, sepsis and inflammatory cascades as cardinal manifestations which do not need any chest physiotherapy rather carry a high risk of aerosol transmission. Patients will be particularly benefitted by physiotherapy during convalescence when breathing exercise, passive and active exercise of musculoskeletal systems will help early step down to ward from ICU thus reducing the length of hospital stay.The COVID-19 outbreak and its impact on health systems mean that health planners need to make decisions on the extent to which rehabilitation services continue to operate and how rehabilitation service continuity can be maximized. Our health care delivery system must develop capacity building of rehabilitation health workforce as well as infrastructure so that we can meet the crisis in a situation like coronavirus pandemic. Ironically our healthcare delivery system do not have priority in rehabilitation services even in this corona pandemic crisis when WHO have clear guidelines on rehabilitation management of COVId-19 patients. We expect a rehabilitation management inclusive national guidelines for corona dedicated hospitals in Bangladesh. We should arrange short training course for rehabilitation specialist so that they can address the post corona complication properly. The potential research areas should be based on management of long COVID complications. The future research should focus on facing the newer variants of corona virus especially rehabilitation perspectives of long COVID complications

\section{References:}

1. Country \& technical guidance - coronavirus disease (COVID-19) [website]. Geneva: World Health Organization;
2020 (https://www.who.int/emergencies/diseases/novelcoronavirus-2019/ technical-guidance).

2. Novel Coronavirus Pneumonia Emergency Response Epidemiology Team. Vital surveillances: the epidemiological characteristics of an outbreak of 2019 novel coronavirus diseases (COVID-19) - China. China CDC Weekly, 2020; 2(8):113-22.

3. Lew Henry L, Oh-Park Mooyeon, Cifu David X. American Journal of Physical Medicine \& Rehabilitation: July 2020 Volume 99 - Issue 7 - p 571-572 doi: 10.1097/ PHM.0000000000001460

4. Jacqui Thornton Covid-19: the challenge of patient rehabilitation afterintensive care BMJ 2020;369:m1787doi: 10.1136/bmj.m1787 (Published 6 May 2020)

5. National Guidelines on Clinical Management of Coronavirus Disease 2019 (COVID-19) Version 6.0 18 May 2020. Disease Control Division Directorate General of Health Services. Ministry of Health \& Family Welfare Government of the People's Republic of Bangladesh

6. $\mathrm{WHO} / 2019-\mathrm{nCoV} / \mathrm{clinical} / 2020.5$

7. 'CARING FOR CRITICALLY ILL COVID- 19 PATIENT: QUICK GUIDE FOR ICU CARE' https://dghs.gov.bd/ images/docs/Notice/27_04_2020.

8. NICE. Rehabilitation after critical illness. NICE Clinical Guideline 83. London: National Institute for Health and Care Excellence; 2009 (http://www.nice.org.uk/guidance/ cg83, accessed 21 May 2020).

9. Bolton CE, Singh SJ, Walker PP, British Thoracic Society Pulmonary Rehabilitation Guideline Group. Commentary: the British Thoracic Society guideline on pulmonary rehabilitation in adults. Thorax. 2013;68(9):887-8. Epub 2013/08/13.

10. Holm SE, Mu K. Discharge Planning for the Elderly in Acute Care: The Perceptions of Experienced Occupational Therapists. Physical \& Occupational Therapy In Geriatrics 2012;30(3):214-28. doi: 10.3109/02703181.2012.719601.

11. World Health Organization, Clinical management of severe acute respiratoryinfection (SARI) when COVID-19 disease is suspected. Interim Guidance, v1.2.2020; WHO reference number: WHO/2019-nCoV/clinical/2020.4

12. Zhou F, Yu T, Du R, et al. Clinical course and risk factors for mortality of adultInpatients with COVID-19 in Wuhan, China: a retrospective cohort study. TheLancet 2020; 395 (10229):1054-62. doi: 10.1016/S0140-6736(20)30566-3

13. Intensive Care National Audit \& Research Centre (ICNARC) report on COVID-19 in critical care (27 March 2020). 2020; IntensiveCare National Audit and Research Centre, London, UK

14. Guan W-j, Ni Z-y, Hu Y, et al. Clinical characteristics of coronavirus disease 2019in China. N Engl J Med March 20, 2020; Published Ahead of Print doi: 10.1056/ NEJMoa2002032 
15. Yang X, Yu Y, Xu J, et al. Clinical course and outcomes of critically ill patientswith SARS-CoV-2 pneumonia in Wuhan, China: a single-centered, retrospective, observational study. Lancet Respiratory Medicine 2020; Published Ahead of Printdoi: 10.1016/S2213-2600(20)30079-5

16. Brower RG. Consequences of bed rest. Crit Care Med 2009;37(10Supp1):S422-8. doi: 10.1097/ CCM.0b013e3181b6e30a 00003246-200910001-00019 [pii] [published Online First: 2010/02/06]

17. Parry SM, El-Ansary D, Cartwright MS, Sarwal A, Berney $\mathrm{S}$, Koopman R;Ultrasonography in the intensive care setting can be used to detect changes in the quality and quantity of muscle and is related to muscle strength and function $\mathrm{J}$ Crit Care 2015 Oct;30(5):1151.e9-14. doi: 10.1016/ j.jcrc.2015.05.024. Epub 2015 Jun 3.

18. Gandotra S, Lovato J, Case D, et al. Physical function trajectories in survivors ofacute respiratory failure. Annals of the American Thoracic Society 2019; 16(4):471-77.doi: 10.1513/AnnalsATS.201806-375OC

19. Dinglas V, Friedman L, Colantuoni E, et al. Muscle weakness and 5-year survival in acute respiratory distress syndrome survivors. Critical Care Medicine; March2017; 45(3):446-53.

20. Herridge MS, Tansey CM, Matté A, et al. Functional disability 5 years after acute respiratory distress syndrome. N Engl J Med 2011; 364(14):1293-304. doi:doi:10.1056/ NEJMoa 1011802

21. Hopkins R, Suchyta M, Kamdar B, et al. Instrumental activities of daily living after critical illness: a systematic review. Annals of the American Thoracic Society2017; 14(8):1332-43. doi: 10.1513/AnnalsATS.201701-059SR

22. Hopkins RO, Weaver LK, Collingridge D, et al. Two-year cognitive, emotional, and quality-of-life outcomes in acute respiratory distress syndrome. Am J RespirCrit Care Med 2005;171(4):340-47. doi: 10.1164/rccm.200406-763OC

23. Uddin, T., Islam, M. T., Rahim, H. R., Islam, M. J., Hossian, M. S., Hassan, M. I., Mamun, M. A. A., Hossain, M. S., Rahman, M. A., \& Chobi, F. K. (2020). Rehabilitation Perspectives of COVID-19 Pandemic in Bangladesh. Journal of Bangladesh College of Physicians and Surgeons, 38, 76-81.

24. Thomas P, Baldwin C, Bissett B, et al. Physiotherapy management for COVID-19 in the acute hospital setting: clinical practice recommendations. Journal of Physiotherapy 2020; Published Ahead of Print doi: https:/ /doi.org/10.1016/j. jphys.2020.03.011
25. Pathmanathan N, Beaumont N, Gratrix A. Respiratory physiotherapy in thecritical care unit. Continuing Education in Anaesthesia Critical Care \& Pain2014;15(1):20-25. doi: 10.1093/bjaceaccp/mku005

26. Terblanche E. The role of dietitians in critical care; Journal of the Intensive CareSociety 2019; 20(3):255-57. doi: $10.1177 / 1751143718774715$

27. McRae J, Montgomery E, Garstang Z, et al. The role of speech and languagetherapists in the intensive care unit. Journal of the Intensive Care Society 2019;Published Ahead of Print doi: 10.1177/1751143719875687

28. Held N, Moss M. Optimizing post-intensive care unit rehabilitation. TurkishThoracic Journal 2019; 20(2):147-52.

29. Griffiths RD, Jones C. Seven lessons from 20 years of follow-up of intensive careunit survivors. Current Opinion in Critical Care 2007; 13(5):508-13. doi: 10.1097/ MCC.0b013e3282efae05

30. Holm SE, Mu K. Discharge Planning for the elderly in acute care: theperceptions of experienced occupational therapists. Physical \& OccupationalTherapy In Geriatrics 2012;30(3):214-28. doi: 10.3109/02703181.2012.719601

31. Bolton CE, Bevan-Smith EF, Blakey JD, et al. British Thoracic Society guidelineon pulmonary rehabilitation in adults: accredited by NICE. Thorax 2013;68(Supp12):ii1ii30. doi: 10.1136/thoraxjnl-2013-203808

32. Rachael Moses, Consultant Respiratory Physiotherapist. COVID 19 and Respiratory Physiotherapy Referral Guideline.Lancashire Teaching Hospitals. Version 1 Dated 17 th March 2020

33. Thomas P, Baldwin C, Bissett B, Boden I, Gosselink R, Granger CL et al, 2020: Physiotherapy management for COVID-19 in the acute hospital setting, recommendations to guide clinical practice. Journal of Physiotherapy, Version 1.0, published 23 March 2020.

34. Messerole E, Peine P, Wittkopp S, Marini JJ, Albert RK. The pragmatics of prone positioning.Am J RespirCrit Care Med 2002 May 15;165(10):1359-63. doi: 10.1164/ rccm. 2107005

35. Borg K, Stam H. Editorial: Covid-19 and Physical and Rehabilitation Medicine. J Rehabil Med. 2020; 52(4):jrm00045. Published 2020 Apr 15. Doi: 10.2340/ 16501977-2679. 